\title{
Liver Resection with Portal Vein Thrombectomy for Hepatocellular Carcinoma With Vascular Invasion
}

\author{
Luca Aldrighetti, MD¹, Carlo Pulitanò, MD ${ }^{1}$, Marco Catena, $\mathbf{M D}^{1}$, Marcella Arru, MD ${ }^{1}$, Eleonora Guzzetti, MD $^{1}$, \\ Jane Halliday, $\mathrm{MD}^{2}$, and Gianfranco Ferla, $\mathrm{MD}^{1}$ \\ ${ }^{1}$ Department of Surgery-Liver Unit, Scientific Institute San Raffaele, Vita-Salute San Raffaele University, Milan, Italy; \\ ${ }^{2}$ NHS, Lothian, United Kingdom
}

\begin{abstract}
Introduction. Hepatocellular carcinoma (HCC) tends to invade the intrahepatic vasculature, especially the portal vein. ${ }^{1}$ The presence of portal vein tumor thrombus (PVTT) in patients with $\mathrm{HCC}$ is one of the most significant factors for a poor prognosis. ${ }^{2-5}$ The presence of macroscopic PVTT in patients with $\mathrm{HCC}$ is also a significant factor for poor prognosis, with a median survival of $<3$ months without treatment. ${ }^{1}$ In surgically resected series, in patients with gross PVTT (PVTT in the portal trunk, its first-order branch, or its second-order branch), the 3-year and 5-year survival rates are reportedly $15 \%$ to $28 \%$ and $0 \%$ to $17 \%$, respectively. ${ }^{2-5}$
\end{abstract}

Methods. The patient was a 77-year-old woman with well-compensated hepatitis $\mathrm{C}$ virus-related cirrhosis (stage A6 according to Child-Pugh classification) who sought care at our department for vague abdominal discomfort. Triphasic spiral computed tomographic scan confirmed HCC 6 $\mathrm{cm}$ in diameter in the left lobe of the liver. In addition, portal vein tumor thrombosis of the left branch that extended to the right portal vein was present.

Results. The procedure included left hepatectomy and enbloc portal vein thrombectomy with clamping of both the

Presented to Annual Meeting of the American Hepato-PancreatoBiliary Association (AHPBA), Miami, Florida, USA, March 9-12, 2006

Electronic supplementary material The online version of this article (doi:10.1245/s10434-009-0383-y) contains supplementary video material, which is available to authorized users.

(C) Society of Surgical Oncology 2009

First Received: 16 July 2008;

Published Online: 10 March 2009

L. Aldrighetti, MD

e-mail: aldrighetti.luca@hsr.it common portal vein trunk and the right portal vein. The portal vein was incised at the bifurcation of the right and left portal veins, and the thrombus was extracted from the incision in the portal vein. With this procedure, we were able to examine under direct vision the exact extent of the portal vein thrombus, and we identified whether the tumor thrombus was adherent to the venous wall or was freely floating in the venous lumen.

Portal clamping and length of operation were 16 and 330 minutes, respectively. Intraoperative blood loss was $550 \mathrm{~mL}$. The patient was discharged on postoperative day 6 , and she was free of disease at 15 months after surgery. Discussion. Liver resection should be considered a valid therapeutic option for HCC with PVTT.

\section{REFERENCES}

1. Llovet JM, Bustamante J, Castells A, et al. Natural history of untreated nonsurgical hepatocellular carcinoma: rationale for the design and evaluation of therapeutic trials Hepatology. 1999;29: $62-7$

2. Ikai I, Yamaoka Y, Yamamoto Y, et al. Surgical intervention for patients with stage IV-A hepatocellular carcinoma without lymph node metastasis: proposal as a standard therapy Ann Surg. 1998; 227:433-9.

3. Chen XP, Qiu FZ, Wu ZD, et al. Effects of location and extension of portal vein tumor thrombus on long-term outcomes of surgical treatment for hepatocellular carcinoma Ann Surg Oncol. 2006;13: 940-6.

4. Le Treut YP, Hardwigsen J, Ananian P, et al. Resection of hepatocellular carcinoma with tumor thrombus in the major vasculature. A European case-control series J Gastrointest Surg. 2006; 10:855-62.

5. Peng B, Liang L, He Q, Zhou F, Luo S. Surgical treatment for hepatocellular carcinoma with portal vein tumor thrombus Hepatogastroenterology. 2006;53:415-9. 